\title{
AN UNUSUALLY LARGE (5kg) BENIGN OVARIAN CYST REMOVED FROM A POSTMENOPAUSAL WOMAN: A CASE REPORT
}

\author{
Amaraja Paranjpe ${ }^{1}$, V. R. Badhwar², Alka Dani ${ }^{3}$
}

\section{HOW TO CITE THIS ARTICLE:}

Amaraja Paranjpe, V. R. Badhwar, Alka Dani. "An Unusually Large (5kg) Benign Ovarian CYST Removed from a Postmenopausal Woman: A Case Report”. Journal of Evolution of Medical and Dental Sciences 2015; Vol. 4, Issue 37, May 07; Page: 6532-6536, DOI: 10.14260/jemds/2015/946

ABSTRACT: A 47 yrs. old woman presented with a huge abdominal lump which was cystic. Ultrasonography confirmed a large cystic tumour without any solid component. CT displayed large loculus of fluid with a few septae filled with clear homogenous fluid. All tumour makers were within normal limits. Here we present an unusual case in which, during exploratory laparotomy, right ovarian cyst was removed followed by hysterectomy and bilateral salpingo oophoerectomy. Cytology confirmed the benign nature of the cyst with a diagnosis of simple serous cystadenoma with no evidence of malignancy.

KEYWORDS: Large benign ovarian cyst, postmenopausal, serous cyst adenoma.

\section{CASE REPORT:}

- A 47 Years old female, post-menopausal since 3 years, P3L3 came to the OPD with the chief complaints of :

- Abdominal Distension since 3 months.

- And pain in abdomen since 2 months which was increased in the last 3-4 days.

- Pt. had no history of post-menopausal bleeding or any other menstrual irregularities.

- Gave no history of fever, burning micturation. No bladder or bowel complaints.

\section{No History of White Discharge Per Vaginum:}

- On Per abdominal examination.

- Abdomen distented up to xiphisternum, 38 weeks size mass felt. Soft cystic to firm in consistency.

- Per speculum examination showed cervix deviated to the left. Minimal white discharge.

- Cervix and vagina healthy.

Per Vaginal Examination showed Cervix Deviated to the left. Uterus was of Normal Size. Retroverted Separate Mass Felt from Right fornix with Soft Cystic in Consistency:

- Her blood picture showed.

- $\mathrm{Hb}-10.3 \mathrm{gm} \%$.

- WBC count -6100 .

- Platelets - 1.93 lacs.

- $\mathrm{RBS}-89 \mathrm{gm} / \mathrm{dl}$.

- $\quad \mathrm{PT}-15$.

- $\quad$ INR -1.2 .

- $\quad$ LFT/RFT - within normal limits.

- Urine routine - Normal.

- Sr. Electrolytes - Within normal limits. 
- PAP smear showed a normal post-menopausal smear not showing any malignant changes.

- CA 125 level was 15.8 (Normal less than 35).

- Other tumour markers were not elevated.

- USG showed a large fluid filled cystic mass with a few septae within measuring $27 \mathrm{~cm}$ by $18 \mathrm{~cm}$ by $12 \mathrm{~cm}$.

\section{The CT Findings were as follows:}

- A large well defined loculus of fluid is seen in abdomen and pelvis. The contained fluid is homogenous and shows a CT value of $25 \mathrm{HU}$. The loculus measures $27 \times 18 \times 12 \mathrm{~cm}$.

- The wall of the loculus shows no abnormal thickening or enhancement and no enhancing interlocular septum.

- The anatomical relations of the loculus are:

- SUERIOR: stomach, liver and pancreas.

- INFERIOR: bladder, uterus.

- ANTERIOR: anterior abdominal wall and large bowel.

- POSTERIOR: aorta, ureters.

- No other abnormality is found. No free fluid in pelvis.

- A decision of exploratory laparotomy was taken and a huge cyst of $5 \mathrm{~kg}$ was seen arising from the right ovary which was removed and later a hysterectomy with bilateral salpingooopherectomy was done. The cyst was weighed and found out to be $5 \mathrm{~kg}$. And a free clear cystic fluid was drained out and sent for cytological examination. The cyst was sent for histopathology and cystological examination.

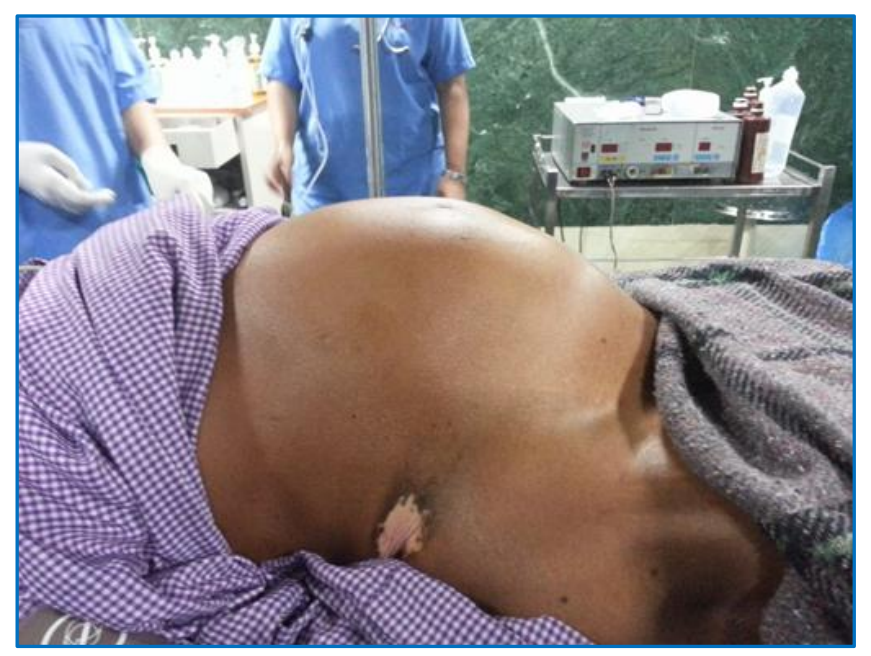

Fig. 1: Pre-operative picture of the enlarged mass 


\section{CASE REPORT}

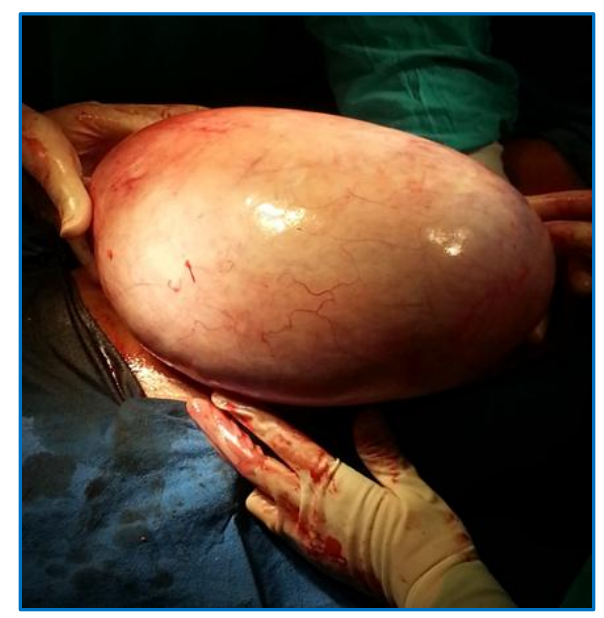

Fig. 2: Intra operative picture of the mass attached to the ovary

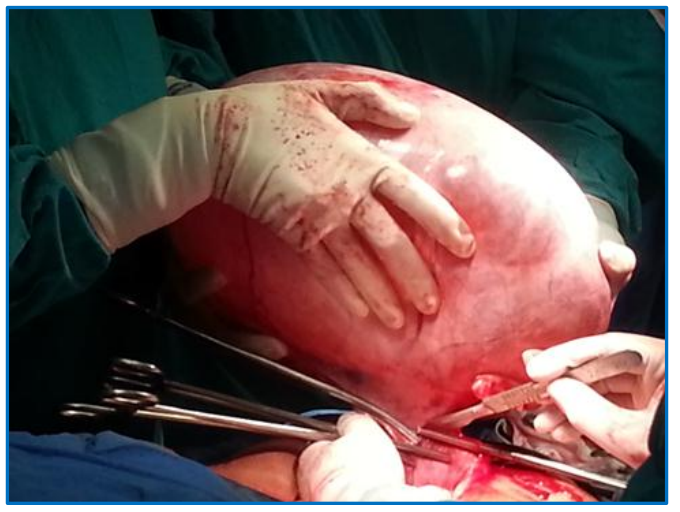

Fig. 3: Separating the cyst from its pedicle

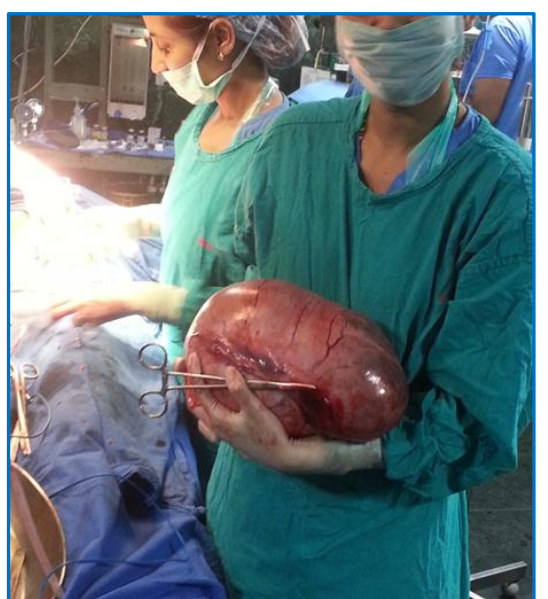

Fig. 4: Picture showing the size of cyst after removal 


\section{CASE REPORT}

- Both tubes and ovaries, and the uterus were healthy. On histopathology, the section of the cyst was thin walled and lined by columnar epithelium and stroma containing spindly fibroblasts.

- Nuclear atypia and increased mitotic index were not observed suggestive of benign serous cystadenoma.

- The sections from the uterus, tubes and the ovaries were normal.

- Postoperative period was uneventful and patient was discharged on tenth day.

\section{DISCUSSION:}

- Giant ovarian serous cyst adenoma of such a huge size is a rare finding.

- The most remarkable descriptions of large ovarian cysts are those of Spohn, who in 1922 reported one that weighed $148.6 \mathrm{~kg}(328 \mathrm{lb})$, and of Symmonds, who in 1963 reported encountering one that weighed $79.4 \mathrm{~kg}(175 \mathrm{lb})$.

- Such descriptions were among the curiosities reported in the $19^{\text {th }}$ and early 20th centuries. They have become rarer as imaging modalities improve and diagnoses are made earlier. ${ }^{1,2}$

- Ovarian epithelial tumors comprise about half of all ovarian tumors, accounting for about $40 \%$ of benign tumors and $86 \%$ of malignant tumors.

- Benign serous tumors include cyst adenomas, adenofibromas, cyst adenofibromas and surface papillomas.

- These tumors are common, accounting for about $25 \%$ of all benign ovarian neoplasms and $58 \%$ of all ovarian serous tumors.

- The serous tumors are bilateral in about $10 \%$ of cases of all serous tumors, about $70 \%$ are benign, $5-10 \%$ have borderline malignant potential and $20-25 \%$ are malignant, depending largely on the patient's age.

- They tend to be multilocular but unilocular serous cyst adenomas are not uncommon. They present grossly as large cysts, spherical or ovoid masses, like the one reported here. ${ }^{3}$

\section{REFERENCES:}

1. Mülayim B, Gürakan H, Dagli V, Mülayim S, Aydin O, Akkaya H: Unaware of a giant serous cyst adenoma: a case report. Arch Gynaecol Obstet 2006, 273: 381-383.

2. S, Shvartzman P: Giant ovarian cyst mimicking ascites. J Fam Pract 1994, 39: 479-481.

3. Young TH, Lee HS: Images in clinical medicine. Giant Ovarian Cyst N Engl J Med 2008, 358: e22. 


\section{AUTHORS:}

1. Amaraja Paranjpe

2. V. R. Badhwar

3. Alka Dani

\section{PARTICULARS OF CONTRIBUTORS:}

1. Registrar, Department of Obstetrics \& Gynaecology, Dr. D. Y. Patil Hospital Nerul Navi Mumbai.

2. Professor \& Head of Unit, Department of Obstetrics \& Gynaecology, Dr. D. Y. Patil Hospital Nerul, Navi Mumbai.

FINANCIAL OR OTHER

COMPETING INTERESTS: None
3. Lecturer, Department of Obstetrics \& Gynaecology, Dr. D. Y. Patil Hospital Nerul Navi, Mumbai.

\section{NAME ADDRESS EMAIL ID OF THE} CORRESPONDING AUTHOR:

Dr. Amaraja Agashe,

44/101, Amrut Vani C.H.S, $15^{\text {th }}$ Road, Chembur, Mumbai- 400071.

E-mail: amaraja.agashe@gmail.com

Date of Submission: 13/04/2015. Date of Peer Review: 14/04/2015. Date of Acceptance: 28/04/2015. Date of Publishing: 07/05/2015. 